OPEN ACCESS

Edited by:

Sue-Hyun Lee,

Korea Advanced Institute of Science and Technology, South Korea

Reviewed by:

Carlos J. Gomez-Ariza, University of Jaén, Spain

Kyriaki Sidiropoulou,

University of Crete, Greece

*Correspondence:

Magdalena Pereyra

magdalenapereyra@gmail.com

Specialty section:

This article was submitted to

Cognitive Neuroscience,

a section of the journal

Frontiers in Human Neuroscience

Received: 22 June 2021

Accepted: 20 August 2021

Published: 21 September 2021

Citation:

Pereyra M and Medina JH (2021)

AMPA Receptors: A Key Piece

in the Puzzle of Memory Retrieval.

Front. Hum. Neurosci. 15:729051.

doi: 10.3389/fnhum.2021.729051

\section{AMPA Receptors: A Key Piece in the Puzzle of Memory Retrieval}

\author{
Magdalena Pereyra ${ }^{1 *}$ and Jorge H. Medina ${ }^{1,2,3}$ \\ ${ }^{1}$ Facultad de Medicina, Universidad de Buenos Aires, Buenos Aires, Argentina, ${ }^{2}$ Instituto de Biología Celular y Neurociencia \\ "Dr. Eduardo De Robertis" (IBCN), CONICET-Universidad de Buenos Aires, Buenos Aires, Argentina, ${ }^{3}$ Instituto Tecnológico \\ de Buenos Aires (ITBA), Buenos Aires, Argentina
}

Retrieval constitutes a highly regulated and dynamic phase in memory processing. Its rapid temporal scales require a coordinated molecular chain of events at the synaptic level that support transient memory trace reactivation. AMPA receptors (AMPAR) drive the majority of excitatory transmission in the brain and its dynamic features match the singular fast timescales of memory retrieval. Here we provide a review on AMPAR contribution to memory retrieval regarding its dynamic movements along the synaptic compartments, its changes in receptor number and subunit composition that take place in activity dependent processes associated with retrieval. We highlight on the differential regulations exerted by AMPAR subunits in plasticity processes and its impact on memory recall.

Keywords: memory retrieval, AMPA receptor, AMPA receptor trafficking, AMPA receptor subunits, memory retrieval mechanisms

\section{INTRODUCTION}

The ability to recall past events is a major determinant of survival strategies in all species and is of paramount importance in determining our uniqueness as individuals. Memory retrieval refers to the complex and active process of re-accessing previously stored information and its expression in the brain. Retrieval is critical for memory: without its retrieval it is not possible to ensure we have a given memory. Furthermore, some reports have revealed that some types of amnesia are associated with memory retrieval rather than consolidation failures (Weiskrantz, 1966; Warrington and Weiskrantz, 1968; Roy et al., 2016). Besides, retrieval constitutes a "gateway" process: it could involve memory trace destabilization (Nader et al., 2000b) that can lead to memory reconsolidation or extinction, two critical stages in memory processing (Nader et al., 2000a; Dudai and Eisenberg, 2004; Tronson and Taylor, 2007; Monfils et al., 2009; Kida, 2020). Whether or not memory destabilization takes place depends on the strength and age of the memory as well as the duration of memory retrieval (Suzuki et al., 2004). Even more, retrieval can trigger forgetting of other memory traces that competes with the one being retrieved in a process called "retrieval-induced forgetting" (RIF) (Anderson, 2003; Bekinschtein et al., 2018; Anderson and Hulbert, 2021). For example, in rats, retrieved memories of an object leads to a reduced retention of other objects seen in the same context (Bekinschtein et al., 2018). In humans, some theories point that RIF could be linked to inhibitory mechanisms that reduce the accessibility of non-target items that interfere with the retrieval of target items whereas other theories point to strength-based competition or blocking (Murayama et al., 2014). 
Memory recall is a very rapid process, since animals retrieve as soon as they receive, usually without notice, the conditioned stimulus (CS) or other cues, including stimuli remindful of the unconditioned stimulus (US) or an emotional context reminiscent of the memory. Indeed, data from human declarative memory studies indicates that the reinstatement of the patterns of activity needed to retrieve is achieved between 500 and $1500 \mathrm{~ms}$ (Staresina and Wimber, 2019). This is clearly a very short timescale compared to other memory processes that could take from minutes to hours (synaptic consolidation), to days or even weeks like systems consolidation (Dudai and Morris, 2000; Squire et al., 2015). Strikingly, there are circumstances in which memory retrieval neural circuit activation could occur without the behavioral output associated, leading to the distinction between memory retrieval and memory expression (Delorenzi et al., 2014).

Memory retrieval involves the reactivation of a relevant number of synapses between learning-activated neurons in various regions of the brain. There is a general consensus that the neuronal activity and synapses that are reactivated when the animals are demanded to retrieve are those that have been changed through the molecular processes that underlie memory formation (Frankland et al., 2019). For those who are interested in what is known about the link between memory formation and retrieval, the multiplicity of brain regions involved in memory retrieval, the interactions between putative "engram cells" and retrieval cues, the neural factors that determine retrieval occurrence, and the consequences of recalling, there are several good review articles dedicated to various aspects of the neurobiology of memory retrieval (Izquierdo et al., 2006; Tronson and Taylor, 2007; Tonegawa et al., 2015; Frankland et al., 2019; Josselyn and Tonegawa, 2020).

Retrieval cues lead to partial reinstatement of the original pattern of neural activity elicited at the moment of encoding (Rugg et al., 2015). In this sense, the overlap between encoding and retrieval neural representations has been proposed in both the transfer-appropriate processing (TAP) and cortical reinstatement hypothesis (Rugg et al., 2008). In particular, theta rhythm has been proposed to set the dynamics for encoding and retrieval within cortical circuits although different phases of hippocampal theta rhythm may enable separation between encoding and retrieval (Hasselmo and Stern, 2014).

In contrast to memory formation, the information about the molecular mechanisms of memory retrieval is surprisingly scarce and fragmentary. In this context, the notion that retrieval constitutes a process as active and involving molecular pathways as intricate as other memory phases is new. In this regard, recent work has revealed the requirement of protein synthesis during memory retrieval (Lopez et al., 2015; Pereyra et al., 2018). Since then, fundamental questions have emerged: Which are the synaptic plasticity proteins whose expression is necessary at the time of retrieval?

The molecular mechanisms of memory retrieval take place in systems that are "ready to go" whenever the animal is demanded to retrieve using pre-existing house-keeping molecules, such as receptors or signaling enzymes. In this review, we will focus on the analysis of some of the molecular mechanisms of memory recall and in particular, we highlight the role of different AMPA receptor (AMPAR) subunits in retrieval of stored information.

\section{MEMORY RETRIEVAL: AN AMPAR STORY}

The most prevalent neurotransmitter in the brain is glutamate, which mostly activates AMPAR. AMPAR consists of four homologous pore-forming subunits (GluA1-4) that generally assemble into heteromers. The presence of GluA2 is of functional importance because it confers calcium impermeability to the AMPAR channel (Isaac et al., 2007). In the CA1 area of the hippocampus, GluA1/GluA2 and GluA2/GluA3 heteromers represent approximately 80 and 20\%, respectively of the postsynaptic response in baseline conditions (Buonarati et al., 2019).

Memory retrieval has been historically associated with changes in AMPAR. In particular, the first works that studied AMPAR role in memory retrieval with pharmacological approaches have addressed AMPAR activation (Table 1; Liang, 1991; Bianchin et al., 1993; Izquierdo et al., 1993, 1997; Kim et al., 1993; Riedel et al., 1999; Szapiro et al., 2000; Yasoshima et al., 2000). Interestingly, these receptors have a very peculiar fast temporal kinetics which lead to a rapid activation that could support recall processes' brief timescales. Compared to NMDAR, AMPAR are not blocked by $\mathrm{Mg} 2+$ and thus they need less depolarization to be activated (Stern and Alberini, 2013). Indeed, AMPAR activation is needed for NMDAR activation.

Our thinking on AMPAR role on synaptic plasticity have been traditionally focused on receptor activity and integrity. However, new technical approaches development has expanded this historical view. In the last three decades, findings coming from advances in labeling postsynaptic surface components (Fujimoto, 1995; Masugi-Tokita et al., 2007) as well as single molecule detection has provided enough evidence about AMPAR mobility between different synaptic compartments and its implications in learning and memory processes (Choquet and Triller, 2013; Penn et al., 2017; Zhang et al., 2018). Also, once inserted in the postsynaptic density (PSD) membrane, AMPAR exhibits a singular clustered aggregation in nanodomains in precise alignment with presynaptic sites that account for efficient synaptic transmission (MacGillavry et al., 2013; Nair et al., 2013). The fact that AMPAR could be exchanged between intra and extrasynaptic compartments (Borgdorff and Choquet, 2002; Petrini et al., 2009; Choquet, 2018) in a fast way made these receptors excellent candidates to underlie the processes involved in memory retrieval that may occur in seconds timescale. Indeed, AMPAR resides as the most mobile among all receptors (Borgdorff and Choquet, 2002). Moreover, modulating AMPAR surface diffusion has been shown to restore memory expression in Huntington Disease model (Zhang et al., 2018).

In the last few years, the focus of AMPAR research has shifted from its mere activation toward its dynamic movements between synapse compartments. A special emphasis has been directed to the role of AMPAR endocytosis (Carroll et al., 2001) in the postsynapse where most surface AMPAR resides (Table 1; 
TABLE 1 | Link between AMPAR changes and memory retrieval reported in the literature.

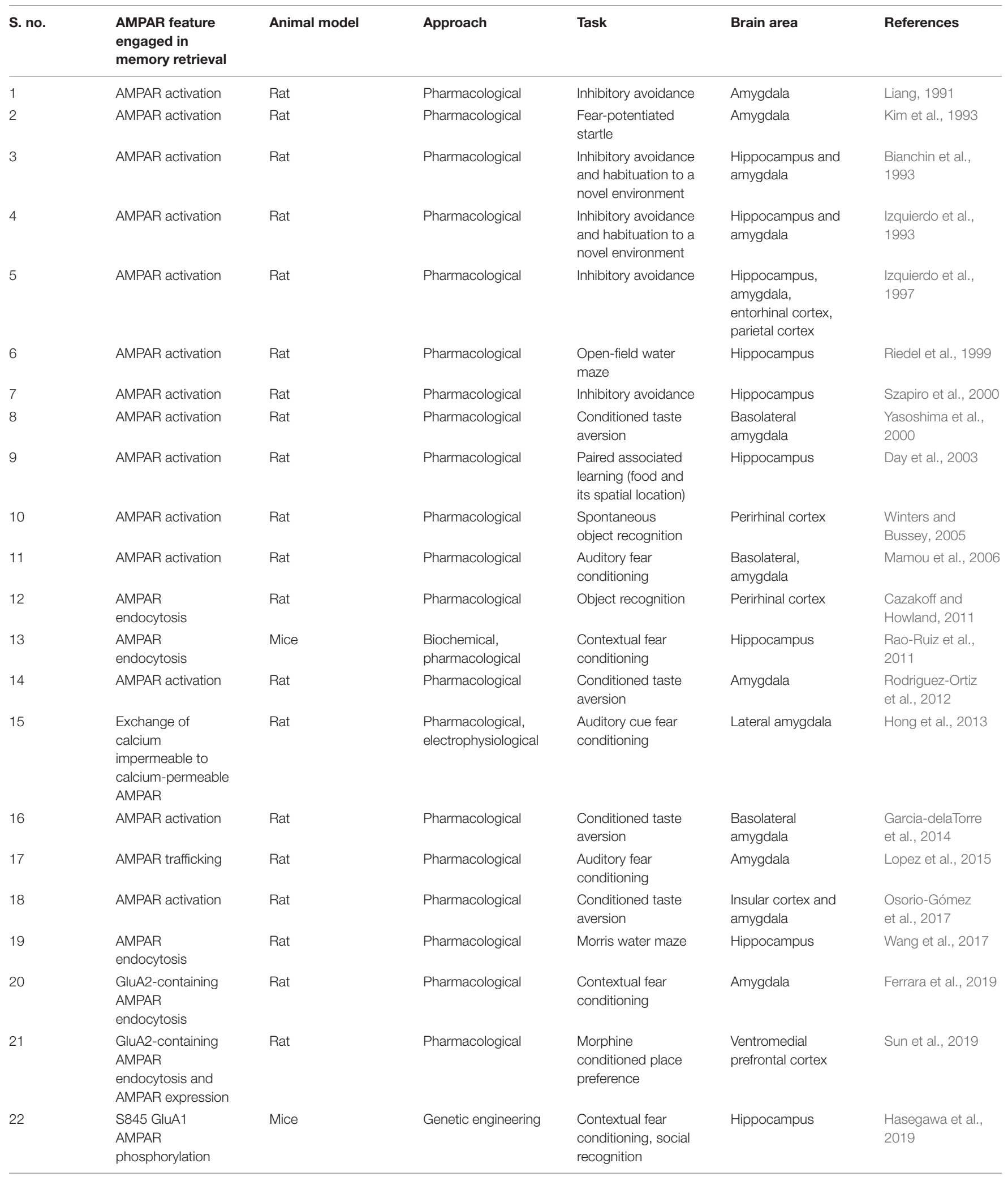


TABLE 1 | (Continued)

\begin{tabular}{|c|c|c|c|c|c|c|}
\hline S. no. & $\begin{array}{l}\text { AMPAR feature } \\
\text { engaged in } \\
\text { memory retrieval }\end{array}$ & Animal model & Approach & Task & Brain area & References \\
\hline 23 & $\begin{array}{l}\text { Calcium-permeable } \\
\text { AMPAR activity }\end{array}$ & Rat & Pharmacological & $\begin{array}{l}\text { Auditory fear } \\
\text { conditioning, } \\
\text { contextual fear } \\
\text { conditioning }\end{array}$ & $\begin{array}{l}\text { Basolateral } \\
\text { amygdala and } \\
\text { hippocampus }\end{array}$ & $\begin{array}{l}\text { Torquatto et al., } \\
2019\end{array}$ \\
\hline 24 & $\begin{array}{l}\text { AMPAR } \\
\text { endocytosis }\end{array}$ & Rat & Pharmacological & Morris water maze & Hippocampus & $\begin{array}{l}\text { Ashourpour et al., } \\
2020\end{array}$ \\
\hline 25 & AMPAR expression & Rat & Pharmacological & $\begin{array}{l}\text { Contextual fear } \\
\text { conditioning }\end{array}$ & $\begin{array}{l}\text { Basolateral } \\
\text { amygdala }\end{array}$ & Guo et al., 2020 \\
\hline 26 & $\begin{array}{l}\text { AMPAR expression } \\
\text { and endocytosis }\end{array}$ & Rat & Pharmacological & Inhibitory avoidance & Hippocampus & Pereyra et al., 2021 \\
\hline 27 & $\begin{array}{l}\text { AMPAR-Gria2 } \\
\text { transcription }\end{array}$ & Mice & $\begin{array}{l}\text { Monosynaptic } \\
\text { tracing, } \\
\text { electrophysiology, } \\
\text { immunochemistry, } \\
\text { and optogenetics }\end{array}$ & $\begin{array}{l}\text { Two choice spatial } \\
\text { discrimination }\end{array}$ & Hippocampus (DG) & Li et al., 2021 \\
\hline 28 & AMPAR trafficking & Mice & $\begin{array}{l}\text { Freeze fracture } \\
\text { replica } \\
\text { immunolabeling }\end{array}$ & $\begin{array}{l}\text { Auditory fear } \\
\text { conditioning }\end{array}$ & Amygdala & $\begin{array}{l}\text { Seewald et al., } \\
2021\end{array}$ \\
\hline
\end{tabular}

Cazakoff and Howland, 2011; Rao-Ruiz et al., 2011; Wang et al., 2017; Ferrara et al., 2019; Sun et al., 2019; Ashourpour et al., 2020; Pereyra et al., 2021). AMPAR activity-dependent trafficking allows subtle changes in number and localization of these postsynaptic receptors, which in turn shapes neural plasticity processes. Since the relatively low number of AMPAR in spines, even a mild alteration in AMPAR internalization could have a great impact on neuronal homeostasis and transmission and hence in behavior (Matsuzaki et al., 2001; Tanaka et al., 2005).

Other important AMPAR features concern its subunit composition. AMPARs consist of four homologous pore-forming subunits (GluA1-4) that generally assemble into heteromers (Rossmann et al., 2011). Different GluA subunits are related with distinctive properties to AMPAR. The presence of GluA2 is of functional importance because it confers calcium impermeability to the AMPAR channel (Isaac et al., 2007). Most AMPARs described in the brain contain GluA2 subunit (Wenthold et al., 1996; Sans et al., 2003; Lu et al., 2009; Rozov et al., 2012). Nevertheless, a small group of AMPAR lacking GluA2 or lacking GluA2 specific editing, have been described as calcium permeable (CP) AMPAR (Sommer et al., 1991; Jonas et al., 1994; Brusa et al., 1995). CP-AMPARs are associated with greater single-channel conductance, faster decay kinetics, and an inwardly rectifying biophysical profile (Liu and Cull-Candy, 2000; Nissen et al., 2010) which make them ideal candidates to account for acute synaptic potentiation. In turn, calcium-impermeable AMPARs (CI-AMPARs) which contains GluA2 subunit are involved in basal synaptic transmission and are more stable at the synapse due to GluA2 subunit interaction with synaptic proteins that promotes the retention of the AMPAR in the membrane (Dong et al., 1997; Nishimune et al., 1998; Shi et al., 2001; Pozo et al., 2012). Consistently, GluA2 subunit has been reported to stabilize dendritic spines (Passafaro et al., 2003; Saglietti et al., 2007). In line with these stability properties differences between CI and CP AMPAR, it has been shown that memory retrieval and its LTP associated processes induce a rapid exchange of CI AMPAR to
CP AMPAR (Shi et al., 2001; Hong et al., 2013). This exchange is known to occur through endocytosis involving the C-terminal tail of GluA2 (Collingridge et al., 2010).

AMPA receptors number, composition and mobility are related to the two major forms of plasticity that underlie memory, long-term potentiation (LTP) and long-term depression (LTD). LTP induces recruitment of AMPAR while LTD is accompanied by internalization of AMPAR (Yuste and Bonhoeffer, 2001; Malinow and Malenka, 2002; Matsuzaki et al., 2004). In this regard, the necessity and sufficiency of GluA1 and GluA2 C-terminal domain for LTP and LTD, respectively with differential implications on spatial and contextual learning and memory has been recently reported (Zhou et al., 2018) even if discrepancies regarding the requirement of C-terminal domain of GluA1 for LTP were reported by other authors (see DíazAlonso et al., 2020). GluA1 trafficking is strongly associated with LTP (Lee et al., 2003; Makino and Malinow, 2009; Huganir and Nicoll, 2013) while GluA2 plays a prominent role in LTD (Diering and Huganir, 2018). It has been shown that optical LTD stimulation can impair memory recall in lateral amygdala whereas LTP stimulation delivery can restore the recall of memory, respectively (Nabavi et al., 2014). Moreover, KIBRA, a gene related with human memory performance has been shown to regulate AMPAR trafficking potentially by affecting LTP and LTD processes (Makuch et al., 2011).

\section{MEMORY RETRIEVAL AND AMPAR SUBUNITS: A MATTER OF TIMING}

Neuron ensembles recruited by learning in the CA1 area of the hippocampus exhibit key synaptic changes such as AMPAR insertion (Whitlock et al., 2006). Among AMPAR subunits, GluA1 is delivered in a very fast mode compared to GluA2 and GluA3 upon field stimulation (Tanaka and Hirano, 2012). Considering the similar neural activation pattern between 
A

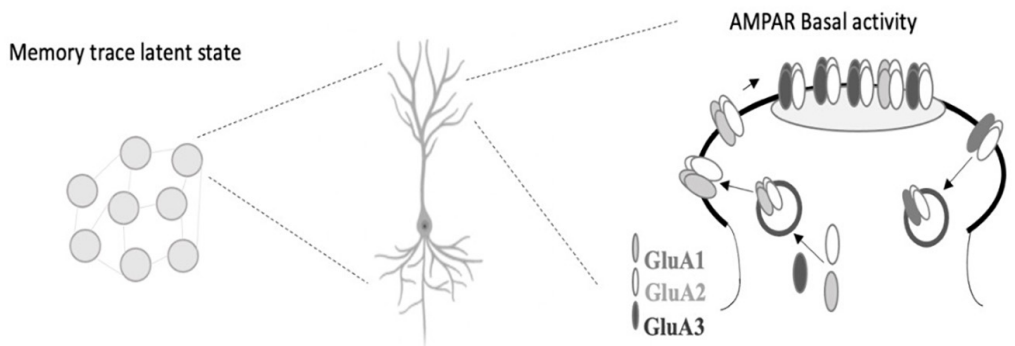

B Memory trace reactivation Memory retrieval (6)
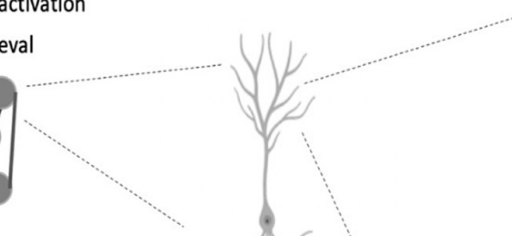

Enhanced mTORC1 mediated GluA1 synthesis

Increased transient GluA1-containing AMPAR formation

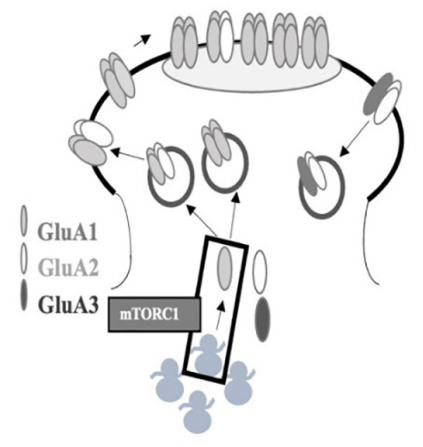

C

Memory trace reactivation Memory retrieval
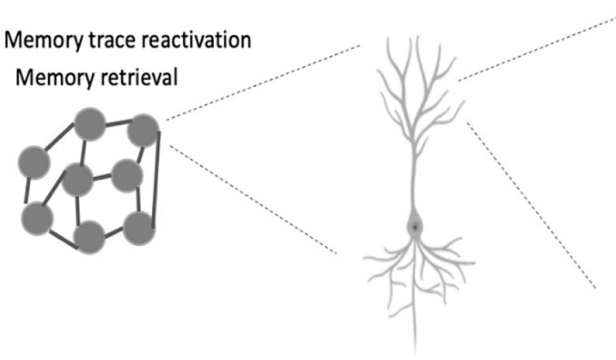

Enhanced transient GluA1-containing AMPAR pool recruitment Enhanced transient GluA1-containing AMPAR exocytosis

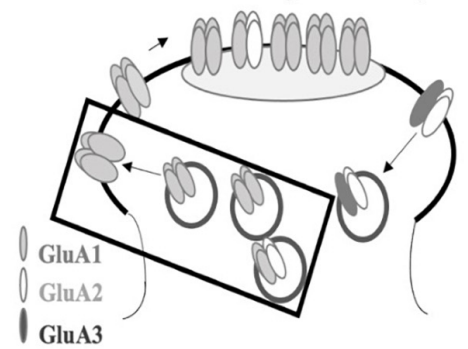

D Memory trace reactivation

Memory retrieval

Enhanced GluA2-containing AMPAR endocytosis
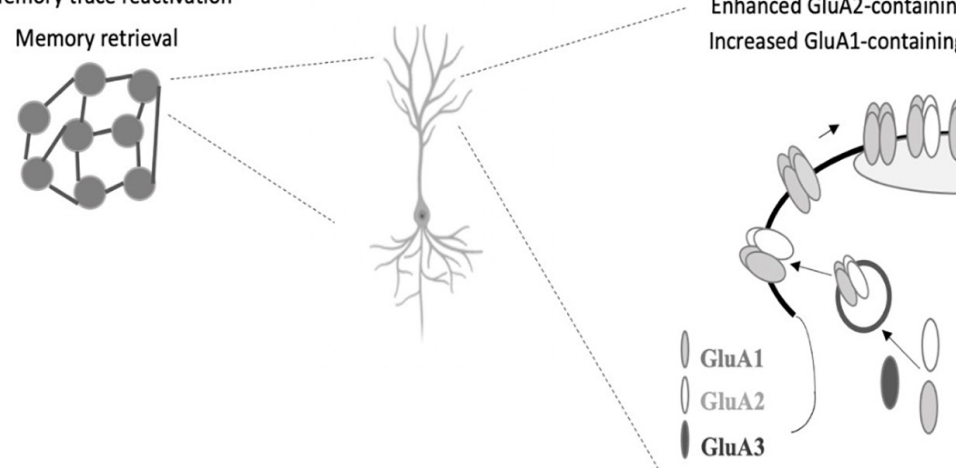

FIGURE 1 | Proposed AMPAR events associated with memory retrieval. (A) In a memory trace latent state, GluA1-containing AMPAR are not enough represented at the postsynaptic density and memory recall does not take place. (B) GluA1 subunit synthesis is needed for memory retrieval to occur (mediated by mTORC1 pathway as we previously reported), which could favor transient GluA1-containing AMPAR formation (especially GluA1 homomers AMPAR) and surface expression which replaces GluA2-containing AMPAR in the postsynaptic density. (C) Alternatively, enhanced GluA1-containing exocytosis may occur in response to activity regulated GluA1-containing AMPAR recruitment. (D) Regulated levels of GluA2-containing AMPAR endocytosis may also account for a greater representation of GluA1-containing AMPAR at the synapse. In all the cases, the proposed AMPAR subunit point alterations lead to GluA2 to GluA1 subunit composition shift during memory retrieval. GluA2 synthesis is also required for memory retrieval although GluA2-containing AMPAR seem to have a support role at the time of retrieval. 
encoding and retrieval and given the fast temporal course of memory retrieval, it is logical to think that GluA1 insertion (Figure 1A) could be considered a critical step for memory retrieval. In this regard, there is a consensus on the need for stable GluA1 levels at the synapse at the time of retrieval (Lopez et al., 2015; Pereyra et al., 2021). Whether these stable levels are achieved by ongoing GluA1 protein synthesis (Lopez et al., 2015; Pereyra et al., 2021) and/or if they are a result of GluA1-AMPAR trafficking (Lopez et al., 2015) or different regulations on GluA1trafficking, such as phosphorylation of GluA1 on Ser 845 by PKA (Man et al., 2007; Hasegawa et al., 2019) or exchange between CI to CP AMPAR (Hong et al., 2013; Torquatto et al., 2019) remains to be elucidated (Figures 1B,C). Moreover, a recent report has demonstrated that Gria2 (the gene that encodes for GluA2 subunit) transcription reduced the efficacy of memory retrieval, likely by promoting a genetic switch from CP to CIAMPAR (Li et al., 2021). To dissect the role of GluA1-containing AMPAR synthesis and insertion in memory retrieval (Figures $\mathbf{1 B}, \mathrm{C}$ ), it would be useful to use GluR $1_{\mathrm{CT}}$, an interference peptide that selectively disrupts GluA1-containing AMPAR exocytosis (Yu et al., 2008; Cui et al., 2011).

We have demonstrated the need of GluA2 subunit ongoing synthesis during memory retrieval (Pereyra et al., 2021). Whether these GluA2 subunits form GluA2-containing AMPAR to be inserted at the moment of retrieval or if they are needed right after memory retrieval to replenish appropriate levels of GluA2-containing AMPAR at the synapse remains to be further elucidated. In any case, it seems logical that GluA2containing AMPAR have a supporting rather than a plasticity drive role at the time of retrieval. Various reports indicate that the infusion of Tat-GluR23y (a selective GluA2-containing AMPAR endocytosis blocker) rescued several memory retrieval deficits (Lopez et al., 2015; Pereyra et al., 2021) (Figure 1D). The memory retrieval rescue effect induced by preventing GluA2containing AMPAR removal remains to be further evaluated. Are these extra retained GluA2-containing AMPAR acting as a reserve pool that then move along the membrane to be recruited in the $\mathrm{PSD}$ ? Or do they contribute to maintaining a balance between different AMPAR subtypes or between AMPAR across different synaptic compartments? Also, the contribution of GluA3-containing AMPAR to plasticity has been less explored (Kessels and Malinow, 2009; Schwenk et al., 2014; Renner et al., 2017) and a differential role evaluation of GluA1/2 and GluA2/3 in memory retrieval has not yet been addressed.

Among the potential upstream modulators of AMPAR movements at the synapse, mTORC1 has been proposed to play a pivotal role in memory processes (Bekinschtein et al., 2007; Lopez et al., 2015; Pereyra et al., 2021). mTORC1 regulates local protein translation in dendrites (Tang et al., 2002; Hay and Sonenberg, 2004; Hoeffer and Klann, 2010; Raab-Graham and Niere, 2017) and its blockade is associated with downregulation of GluA1 levels during memory retrieval in the PSD (Lopez et al., 2015; Pereyra et al., 2021) (Figure 1B). In the hippocampus, but not in the amygdala, downregulation of GluA1 levels is also observed in the synaptic plasma membrane fraction in rapamycin (selective mTORC1 inhibitor)-treated animals (Lopez et al., 2015; Pereyra et al., 2021). Infusion of Tat-GluR23y rescued mTORC1 blockade effects on memory retrieval while showing no effect on memory retrieval alone (Lopez et al., 2015; Pereyra et al., 2021). Nevertheless, a work has shown that infusion of Tat-GluR23y in the perirhinal cortex impaired object recognition memory retrieval (Cazakoff and Howland, 2011). Further questions in this direction are still unsolved: are AMPAR-mediated retrieval mechanisms brain region and/or memory valence specific? mTORC1 local control of AMPAR subunit translation seems compatible on a temporal scale with the memory retrieval molecular events that occur in the synapse and could provide a rapid synthesis rate that assures AMPAR pools that could be recruited in an activity dependent way.

Another factor to take into account when analyzing AMPAR exchanges lies in the stability of the tetramers once inserted in the membrane. A study that uses single molecule imaging has reported that AMPAR membrane tetramers would be metastable complexes that are in dynamic equilibrium with their respective monomers and dimers (Morise et al., 2019). This would imply dissociations of the AMPARs that allow changes in subunit composition at a very fast rate. Finally, different characteristics and regulatory mechanisms of the different AMPAR subunits (Hirano, 2018) can influence the assembly, insertion, lateral diffusion, and endocytosis rate of AMPAR and thus the associated molecular events that account for memory retrieval.

It is also interesting to evaluate the different AMPAR subunits role in some types of memory forgetting that usually represents a reversible memory retrieval disruption (Li et al., 2014; Guskjolen, 2016; Roy et al., 2016). For example, GluA2-containing AMPAR endocytosis mediates memory forgetting (Hardt et al., 2014; Dong et al., 2015; Migues et al., 2016) while blocking this phenomenon reverses memory retrieval deficits (Lopez et al., 2015; Pereyra et al., 2021). Besides, GluA2-containing AMPAR removal has been proposed to contribute to neuron excitability decrease inducing forgetting (Frankland et al., 2013).

\section{CONCLUDING REMARKS}

In this review, we have mainly focused on findings coming from rodent studies. Understanding the molecular basis of memory retrieval is extremely important to fulfill the gap between basic and clinical research. Potential clinical applications include the development of new or more precise targets for the treatment of human memory retrieval pathologies or dysfunction.

Memory recall represents an attractive therapeutic time window for potential translational interventions. Retrieval enables both memory updating and weakening. In this regard, involuntary memory retrieval of a traumatic event is one hallmark symptom of posttraumatic stress disorder (American Psychiatric Association, 2013). Also, memory retrieval deficit has been reported in early stages of Alzheimer mouse model (Roy et al., 2016). On the other hand, there are few reports that address memory retrieval enhancement (Izquierdo et al., 2001, 2003; Barros et al., 2002, 2003; Stern and Alberini, 2013).

Regarding potential memory retrieval enhancement, ampakines, small molecules that positively regulate AMPAR, 
have been widely evaluated in a variety of rodent models and human studies as a therapeutic avenue for treating memory disorders and to enhance cognitive function (Lynch and Gall, 2006; Lynch et al., 2011, 2014; Seese et al., 2020). For instance, CX-691, a specific ampakine, has been shown to improve memory in a rodent model of Alzheimer (Mozafari et al., 2018). In humans, CX-691 has been shown to acutely improve short-term memory in healthy elderly volunteers (Wezenberg et al., 2007). Ampakine S18986 has shown a memory-enhancing effect on performance and reversed memory impairment induced by aging in a contextual and serial discrimination task that serves as model of declarative memory in mice (Tronche et al., 2010).

Further comprehension on AMPAR-mediated plasticity mechanisms will shed light on more selective potential targets (Zhang and Bramham, 2020) regarding memory retrieval deficits associated with neurological diseases.

\section{REFERENCES}

American Psychiatric Association (2013). Diagnostic and Statistical Manual of Mental Disorders: DSM-5. Virginia, VA: APA.

Anderson, M. C. (2003). Rethinking interference theory: executive control and the mechanisms of forgetting. J. Memory Lang. 49, 415-445.

Anderson, M. C., and Hulbert, J. C. (2021). Active forgetting: adaptation of memory by prefrontal control. Annu. Rev. Psychol. 72, 1-36. doi: 10.1146/ annurev-psych-072720-094140

Ashourpour, F., Jafari, A., and Babaei, P. (2020). Co-treatment of AMPA endocytosis inhibitor and GluN2B antagonist facilitate consolidation and retrieval of memory impaired by $\beta$ amyloid peptide. Int. J. Neurosci. doi: 10. 1080/00207454.2020.1837800 Online ahead of print.

Barros, D. M., Izquierdo, L. A., Medina, J. H., and Izquierdo, I. (2002). Bupropion and sertraline enhance retrieval of recent and remote long-term memory in rats. Behav. Pharmacol. 13, 215-220. doi: 10.1097/00008877-200205000-200205004

Barros, D. M., Izquierdo, L. A., Medina, J. H., and Izquierdo, I. (2003). Pharmacological findings contribute to the understanding of the main physiological mechanisms of memory retrieval. Curr. Drug Targets-CNS Neurol. Disorders 2, 81-94. doi: 10.2174/1568007033482931

Bekinschtein, P., Katche, C., Slipczuk, L. N., Igaz, L. M., Cammarota, M., Izquierdo, I., et al. (2007). mTOR signaling in the hippocampus is necessary for memory formation. Neurobiol. Learn. Mem. 87, 303-307. doi: 10.1016/j.nlm.2006.08.007

Bekinschtein, P., Weisstaub, N. V., Gallo, F., Renner, M., and Anderson, M. C. (2018). A retrieval-specific mechanism of adaptive forgetting in the mammalian brain. Nat. Commun. 9:4660. doi: 10.1038/s41467-018-07128-7127

Bianchin, M., Walz, R., Ruschel, A. C., Zanatta, M. S., Da Silva, R. C., e Silva, M. B., et al. (1993). Memory expression is blocked by the infusion of CNQX into the hippocampus and/or the amygdala up to 20 days after training. Behav. Neural Biol. 59, 83-86. doi: 10.1016/0163-1047(93)90782-d

Borgdorff, A. J., and Choquet, D. (2002). Regulation of AMPA receptor lateral movements. Nature 417, 649-653. doi: 10.1038/nature00780

Brusa, R., Zimmermann, F., Koh, D. S., Feldmeyer, D., Gass, P., Seeburg, P. H., et al. (1995). Early-onset epilepsy and postnatal lethality associated with an editingdeficient GluR-B allele in mice. Science 270, 1677-1680. doi: 10.1126/science. 270.5242.1677

Buonarati, O. R., Hammes, E. A., Watson, J. F., Greger, I. H., and Hell, J. W. (2019). Mechanisms of postsynaptic localization of AMPA-type glutamate receptors and their regulation during long-term potentiation. Sci. Signal. 12:eaar6889. doi: 10.1126/scisignal.aar6889

Carroll, R. C., Beattie, E. C., von Zastrow, M., and Malenka, R. C. (2001). Role of AMPA receptor endocytosis in synaptic plasticity. Nat. Rev. Neurosci. 2, 315-324. doi: $10.1038 / 35072500$

Cazakoff, B. N., and Howland, J. G. (2011). AMPA receptor endocytosis in rat perirhinal cortex underlies retrieval of object memory. Learn. Memory 18, 688-692. doi: 10.1101/lm.2312711

\section{AUTHOR CONTRIBUTIONS}

MP and JHM conceived the content. MP performed bibliography research and wrote the manuscript. JHM organized and corrected the manuscript. Both authors contributed to the article and approved the submitted version.

\section{FUNDING}

This Mini Review was supported by grants from Agencia Nacional de Promoción Científica y Tecnológica (ANPCyT, Argentina) to JHM; 2016-0034 and the Argentina National Research Council (Consejo Nacional de Investigaciones Científicas y Técnicas, CONICET).

Choquet, D. (2018). Linking nanoscale dynamics of AMPA receptor organization to plasticity of excitatory synapses and learning. J. Neurosci. 38, 9318-9329. doi: 10.1523/JNEUROSCI.2119-18.2018

Choquet, D., and Triller, A. (2013). The dynamic synapse. Neuron 80, 691-703. doi: 10.1016/j.neuron.2013.10.013

Collingridge, G. L., Peineau, S., Howland, J. G., and Wang, Y. T. (2010). Long-term depression in the CNS. Nat. Rev. Neurosci. 11, 459-473. doi: 10.1038/nrn2867

Cui, W., Darby-King, A., Grimes, M. T., Howland, J. G., Wang, Y. T., McLean, J. H., et al. (2011). Odor preference learning and memory modify GluA1 phosphorylation and GluA1 distribution in the neonate rat olfactory bulb: testing the AMPA receptor hypothesis in an appetitive learning model. Learn. Memory 18, 283-291. doi: 10.1101/lm.1987711

Day, M., Langston, R., and Morris, R. G. (2003). Glutamate-receptor-mediated encoding and retrieval of paired-associate learning. Nature 424, 205-209. doi: 10.1038 /nature01769

Delorenzi, A., Maza, F. J., Suárez, L. D., Barreiro, K., Molina, V. A., and Stehberg, J. (2014). Memory beyond expression. J. Physiology-Paris 108, 307-322. doi: 10.1016/j.jphysparis.2014.07.002

Díaz-Alonso, J., Morishita, W., Incontro, S., Simms, J., Holtzman, J., Gill, M., et al. (2020). Long-term potentiation is independent of the C-tail of the GluA1 AMPA receptor subunit. eLife 9:e58042. doi: 10.7554/eLife.58042

Diering, G. H., and Huganir, R. L. (2018). The AMPA receptor code of synaptic plasticity. Neuron 100, 314-329. doi: 10.1016/j.neuron.2018.10.018

Dong, H., O’Brien, R. J., Fung, E. T., Lanahan, A. A., Worley, P. F., and Huganir, R. L. (1997). GRIP: a synaptic PDZ domain-containing protein that interacts with AMPA receptors. Nature 386, 279-284. doi: 10.1038/386279a0

Dong, Z., Han, H., Li, H., Bai, Y., Wang, W., Tu, M., et al. (2015). Long-term potentiation decay and memory loss are mediated by AMPAR endocytosis. J. Clin. Invest. 125, 234-247. doi: 10.1172/JCI77888

Dudai, Y., and Eisenberg, M. (2004). Rites of passage of the engram: reconsolidation and the lingering consolidation hypothesis. Neuron 44, 93-100. doi: 10.1016/j.neuron.2004.09.003

Dudai, Y., and Morris, R. G. (2000). "To consolidate or not to consolidate: what are the questions?", in Brain Perception Memory Advances in Cognitive Neuroscience, ed. J. J. Bulhuis (Oxford: Oxford University Press), $149-162$.

Ferrara, N. C., Jarome, T. J., Cullen, P. K., Orsi, S. A., Kwapis, J. L., Trask, S., et al. (2019). GluR2 endocytosis-dependent protein degradation in the amygdala mediates memory updating. Sci. Rep. 9:5180. doi: 10.1038/s41598-019-4152641521

Frankland, P. W., Josselyn, S. A., and Köhler, S. (2019). The neurobiological foundation of memory retrieval. Nat. Neurosci. 22, 1576-1585. doi: 10.1038/ s41593-019-0493-491

Frankland, P. W., Köhler, S., and Josselyn, S. A. (2013). Hippocampal neurogenesis and forgetting. Trends Neurosci. 36, 497-503. doi: 10.1016/j.tins.2013.05.002

Fujimoto, K. (1995). Freeze-fracture replica electron microscopy combined with SDS digestion for cytochemical labeling of integral membrane proteins. 
application to the immunogold labeling of intercellular junctional complexes. J. Cell Sci. 108, 3443-3449.

Garcia-delaTorre, P., Pérez-Sánchez, C., Guzmán-Ramos, K., and BermúdezRattoni, F. (2014). Role of glutamate receptors of central and basolateral amygdala nuclei on retrieval and reconsolidation of taste aversive memory. Neurobiol. Learn. Mem. 111, 35-40. doi: 10.1016/j.nlm.2014.03.003

Guo, H., Yuan, K., Zhang, Z., Xue, Y., Yan, W., Meng, S., et al. (2020). Pi4KII $\alpha$ regulates unconditioned stimulus-retrieval-induced fear memory reconsolidation through endosomal trafficking of AMPA receptors. iscience 23:100895. doi: 10.1016/j.isci.2020.100895

Guskjolen, A. J. (2016). Losing connections, losing memory: ampa receptor endocytosis as a neurobiological mechanism of forgetting. J. Neurosci. 36, 7559-7561. doi: 10.1523/JNEUROSCI.1445-16.2016

Hardt, O., Nader, K., and Wang, Y. T. (2014). GluA2-dependent AMPA receptor endocytosis and the decay of early and late long-term potentiation: possible mechanisms for forgetting of short-and long-term memories. Philos. Trans. $R$. Soc. B: Biol. Sci. 369:20130141. doi: 10.1098/rstb.2013.0141

Hasegawa, S., Fukushima, H., Hosoda, H., Serita, T., Ishikawa, R., Rokukawa, T., et al. (2019). Hippocampal clock regulates memory retrieval via dopamine and PKA-induced GluA1 phosphorylation. Nat. Commun. 10:5766. doi: 10.1038/ s41467-019-13554-y

Hasselmo, M. E., and Stern, C. E. (2014). Theta rhythm and the encoding and retrieval of space and time. Neuroimage 85, 656-666. doi: 10.1016/j.neuroimage. 2013.06.022

Hay, N., and Sonenberg, N. (2004). Upstream and downstream of mTOR. Genes Dev. 18, 1926-1945. doi: 10.1101/gad.1212704

Hirano, T. (2018). Visualization of exo-and endocytosis of AMPA receptors during hippocampal synaptic plasticity around postsynaptic-like membrane formed on glass surface. Front. Cell. Neurosci. 12:442. doi: 10.3389/fncel.2018.00442

Hoeffer, C. A., and Klann, E. (2010). mTOR signaling: at the crossroads of plasticity, memory and disease. Trends Neurosci. 33, 67-75. doi: 10.1016/j.tins.2009.11. 003

Hong, I., Kim, J., Kim, J., Lee, S., Ko, H. G., Nader, K., et al. (2013). AMPA receptor exchange underlies transient memory destabilization on retrieval. Proc. Natl. Acad. Sci. U S A. 110, 8218-8223. doi: 10.1073/pnas.1305235110

Huganir, R. L., and Nicoll, R. A. (2013). AMPARs and synaptic plasticity: the last 25 years. Neuron 80, 704-717. doi: 10.1016/j.neuron.2013.10.025

Isaac, J. T., Ashby, M. C., and McBain, C. J. (2007). The role of the GluR2 subunit in AMPA receptor function and synaptic plasticity. Neuron 54, 859-871. doi: 10.1016/j.neuron.2007.06.001

Izquierdo, I., Bevilaqua, L. R., Rossato, J. I., Bonini, J. S., Medina, J. H., and Cammarota, M. (2006). Different molecular cascades in different sites of the brain control memory consolidation. Trends Neurosci. 29, 496-505. doi: 10. 1016/j.tins.2006.07.005

Izquierdo, I., Da Silva, R. C., e Silva, M. B., Quillfeldt, J. A., and Medina, J. H. (1993). Memory expression of habituation and of inhibitory avoidance is blocked by CNQX infused into the entorhinal cortex. Behav. Neural Biol. 60, 5-8. doi: 10.1016/0163-1047(93)90651-w

Izquierdo, I., Quillfeldt, J. A., Zanatta, M. S., Quevedo, J., Schaeffer, E., Schmitz, P. K., et al. (1997). Sequential role of hippocampus and amygdala, entorhinal cortex and parietal cortex in formation and retrieval of memory for inhibitory avoidance in rats. Eur. J. Neurosci. 9, 786-793.

Izquierdo, L. A., Barros, D. M., Medina, J. H., and Izquierdo, I. (2003). Exposure to novelty enhances retrieval of very remote memory in rats. Neurobiol. Learn. Mem. 79, 51-56. doi: 10.1016/s1074-7427(02)00006-0

Izquierdo, L. A., Viola, H., Barros, D. M., Alonso, M., Vianna, M. R. M., Furman, M., et al. (2001). Novelty enhances retrieval: molecular mechanisms involved in rat hippocampus. Eur. J. Neurosci. 13, 1464-1467. doi: 10.1046/j.0953-816x. 2001.01530.x

Jonas, P., Racca, C., Sakmann, B., Seeburg, P. H., and Monyer, H. (1994). Differences in Ca2+ permeability of AMPA-type glutamate receptor channels in neocortical neurons caused by differential GluR-B subunit expression. Neuron 12, 1281-1289. doi: 10.1016/0896-6273(94)90444-90448

Josselyn, S. A., and Tonegawa, S. (2020). Memory engrams: recalling the past and imagining the future. Science 367:eaaw4325. doi: 10.1126/science.aaw4325

Kessels, H. W., and Malinow, R. (2009). Synaptic AMPA receptor plasticity and behavior. Neuron 61, 340-350. doi: 10.1016/j.neuron.2009.01.015
Kida, S. (2020). Function and mechanisms of memory destabilization and reconsolidation after retrieval. Proc. Japan Acad. Series B 96, 95-106. doi: 10. 2183/pjab.96.008

Kim, M., Campeau, S., Falls, W. A., and Davis, M. (1993). Infusion of the nonNMDA receptor antagonist CNQX into the amygdala blocks the expression of fear-potentiated startle. Behav. Neural Biol. 59, 5-8. doi: 10.1016/0163-1047(93) 91075-x

Lee, H. K., Takamiya, K., Han, J. S., Man, H., Kim, C. H., Rumbaugh, G., et al. (2003). Phosphorylation of the AMPA receptor GluR1 subunit is required for synaptic plasticity and retention of spatial memory. Cell 112, 631-643. doi: 10.1016/s0092-8674(03)00122-123

Li, S., Callaghan, B. L., and Richardson, R. (2014). Infantile amnesia: forgotten but not gone. Learn. Memory 21, 135-139. doi: 10.1101/lm.031096.113

Li, X., Chen, W., Yu, Q., Zhang, Q., Zhang, T., Huang, X., et al. (2021). A circuit of mossy cells controls the efficacy of memory retrieval by Gria2I inhibition of Gria2. Cell Rep. 34:108741. doi: 10.1016/j.celrep.2021.108741

Liang, K. C. (1991). Pretest intra-amygdala injection of lidocaine or glutamate antagonists impairs retention performance in an inhibitory avoidance task. Soc. Neurosci. Abstracts 17, 237-249.

Liu, S. Q. J., and Cull-Candy, S. G. (2000). Synaptic activity at calcium-permeable AMPA receptors induces a switch in receptor subtype. Nature 405, 454-458. doi: 10.1038/35013064

Lopez, J., Gamache, K., Schneider, R., and Nader, K. (2015). Memory retrieval requires ongoing protein synthesis and NMDA receptor activity-mediated AMPA receptor trafficking. J. Neurosci. 35, 2465-2475. doi: 10.1523/ JNEUROSCI.0735-14.2015

Lu, W., Shi, Y., Jackson, A. C., Bjorgan, K., During, M. J., Sprengel, R., et al. (2009). Subunit composition of synaptic AMPA receptors revealed by a single-cell genetic approach. Neuron 62, 254-268. doi: 10.1016/j.neuron.2009. 02.027

Lynch, G., Cox, C. D., and Gall, C. M. (2014). Pharmacological enhancement of memory or cognition in normal subjects. Front. Systems Neurosci. 8:90. doi: 10.3389/fnsys.2014.00090

Lynch, G., and Gall, C. M. (2006). Ampakines and the threefold path to cognitive enhancement. Trends Neurosci. 29, 554-562. doi: 10.1016/j.tins.2006.07.007

Lynch, G., Palmer, L. C., and Gall, C. M. (2011). The likelihood of cognitive enhancement. Pharmacol. Biochem. Behav. 99, 116-129. doi: 10.1016/j.pbb. 2010.12.024

MacGillavry, H. D., Song, Y., Raghavachari, S., and Blanpied, T. A. (2013). Nanoscale scaffolding domains within the postsynaptic density concentrate synaptic AMPA receptors. Neuron 78, 615-622. doi: 10.1016/j.neuron.2013.03. 009

Makino, H., and Malinow, R. (2009). AMPA receptor incorporation into synapses during LTP: the role of lateral movement and exocytosis. Neuron 64, 381-390. doi: 10.1016/j.neuron.2009.08.035

Makuch, L., Volk, L., Anggono, V., Johnson, R. C., Yu, Y., Duning, K., et al. (2011). Regulation of AMPA receptor function by the human memoryassociated gene KIBRA. Neuron 71, 1022-1029. doi: 10.1016/j.neuron.2011. 08.017

Malinow, R., and Malenka, R. C. (2002). AMPA receptor trafficking and synaptic plasticity. Annu. Rev. Neurosci. 25, 103-126. doi: 10.1146/annurev.neuro.25. 112701.142758

Mamou, C. B., Gamache, K., and Nader, K. (2006). NMDA receptors are critical for unleashing consolidated auditory fear memories. Nat. Neurosci. 9, 1237-1239. doi: $10.1038 / \mathrm{nn} 1778$

Man, H. Y., Sekine-Aizawa, Y., and Huganir, R. L. (2007). Regulation of $\alpha$-amino-3hydroxy-5-methyl-4-isoxazolepropionic acid receptor trafficking through PKA phosphorylation of the Glu receptor 1 subunit. Proc. Natl. Acad. Sci. U S A. 104, 3579-3584. doi: 10.1073/pnas.0611698104

Masugi-Tokita, M., Tarusawa, E., Watanabe, M., Molnár, E., Fujimoto, K., and Shigemoto, R. (2007). Number and density of AMPA receptors in individual synapses in the rat cerebellum as revealed by SDS-digested freeze-fracture replica labeling. J. Neurosci. 27, 2135-2144. doi: 10.1523/JNEUROSCI.2861-06. 2007

Matsuzaki, M., Ellis-Davies, G. C., Nemoto, T., Miyashita, Y., Iino, M., and Kasai, H. (2001). Dendritic spine geometry is critical for AMPA receptor expression in hippocampal CA1 pyramidal neurons. Nat. Neurosci. 4, 1086-1092. 
Matsuzaki, M., Honkura, N., Ellis-Davies, G. C., and Kasai, H. (2004). Structural basis of long-term potentiation in single dendritic spines. Nature 429, 761-766. doi: $10.1038 /$ nature02617

Migues, P. V., Liu, L., Archbold, G. E., Einarsson, E. Ö, Wong, J., Bonasia, K., et al. (2016). Blocking synaptic removal of GluA2-containing AMPA receptors prevents the natural forgetting of long-term memories. J. Neurosci. 36, 34813494. doi: 10.1523/JNEUROSCI.3333-15.2016

Monfils, M. H., Cowansage, K. K., Klann, E., and LeDoux, J. E. (2009). Extinctionreconsolidation boundaries: key to persistent attenuation of fear memories. Science 324, 951-955. doi: 10.1126/science.1167975

Morise, J., Suzuki, K. G., Kitagawa, A., Wakazono, Y., Takamiya, K., Tsunoyama, T. A., et al. (2019). AMPA receptors in the synapse turnover by monomer diffusion. Nat. Commun. 10:5245. doi: 10.1038/s41467-019-13229-13228

Mozafari, N., Shamsizadeh, A., Fatemi, I., Allahtavakoli, M., Moghadam-Ahmadi, A., Kaviani, E., et al. (2018). CX691, as an AMPA receptor positive modulator, improves the learning and memory in a rat model of Alzheimer's disease. Iranian J. Basic Med. Sci. 21:724. doi: 10.22038/IJBMS.2018.28544.6934

Murayama, K., Miyatsu, T., Buchli, D., and Storm, B. C. (2014). Forgetting as a consequence of retrieval: a meta-analytic review of retrieval-induced forgetting. Psychol. Bull. 140:1383. doi: 10.1037/a0037505

Nabavi, S., Fox, R., Alfonso, S., Aow, J., and Malinow, R. (2014). GluA1 trafficking and metabotropic NMDA: addressing results from other laboratories inconsistent with ours. Philos. Trans. R. Soc. B: Biol. Sci. 369:20130145. doi: 10.1098/rstb.2013.0145

Nader, K., Schafe, G. E., and Le Doux, J. E. (2000b). The labile nature of consolidation theory. Nat. Rev. Neurosci. 1, 216-219. doi: 10.1038/35044580

Nader, K., Schafe, G. E., and Le Doux, J. E. (2000a). Fear memories require protein synthesis in the amygdala for reconsolidation after retrieval. Nature 406, 722-726. doi: 10.1038/35021052

Nair, D., Hosy, E., Petersen, J. D., Constals, A., Giannone, G., Choquet, D., et al. (2013). Super-resolution imaging reveals that AMPA receptors inside synapses are dynamically organized in nanodomains regulated by PSD95. J. Neurosci. 33, 13204-13224. doi: 10.1523/JNEUROSCI.2381-12.2013

Nishimune, A., Isaac, J. T., Molnar, E., Noel, J., Nash, S. R., Tagaya, M., et al. (1998). NSF binding to GluR2 regulates synaptic transmission. Neuron 21, 87-97. doi: 10.1016/s0896-6273(00)80517-80516

Nissen, W., Szabo, A., Somogyi, J., Somogyi, P., and Lamsa, K. P. (2010). Cell type-specific long-term plasticity at glutamatergic synapses onto hippocampal interneurons expressing either parvalbumin or CB1 cannabinoid receptor. J. Neurosci. 30, 1337-1347. doi: 10.1523/JNEUROSCI.3481-09.2010

Osorio-Gómez, D., Guzmán-Ramos, K., and Bermúdez-Rattoni, F. (2017). Memory trace reactivation and behavioral response during retrieval are differentially modulated by amygdalar glutamate receptors activity: interaction between amygdala and insular cortex. Learn. Memory 24, 14-23. doi: 10.1101/ $\operatorname{lm} .042895 .116$

Passafaro, M., Nakagawa, T., Sala, C., and Sheng, M. (2003). Induction of dendritic spines by an extracellular domain of AMPA receptor subunit GluR2. Nature 424, 677-681. doi: 10.1038/nature01781

Penn, A. C., Zhang, C. L., Georges, F., Royer, L., Breillat, C., Hosy, E., et al. (2017). Hippocampal LTP and contextual learning require surface diffusion of AMPA receptors. Nature 549, 384-388. doi: 10.1038/nature23658

Pereyra, M., de Landeta, A. B., Dalto, J. F., Katche, C., and Medina, J. H. (2021). AMPA receptor expression requirement during long-term memory retrieval and its association with mTORC1 signaling. Mol. Neurobiol. 58, 1711-1722. doi: 10.1007/s12035-020-02215-2217

Pereyra, M., Katche, C., de Landeta, A. B., and Medina, J. H. (2018). mTORC1 controls long-term memory retrieval. Sci. Rep. 8:8759. doi: 10.1038/s41598018-27053-27055

Petrini, E. M., Lu, J., Cognet, L., Lounis, B., Ehlers, M. D., and Choquet, D. (2009). Endocytic trafficking and recycling maintain a pool of mobile surface AMPA receptors required for synaptic potentiation. Neuron 63, 92-105. doi: 10.1016/j.neuron.2009.05.025

Pozo, K., Cingolani, L. A., Bassani, S., Laurent, F., Passafaro, M., and Goda, Y. (2012). $\beta 3$ integrin interacts directly with GluA2 AMPA receptor subunit and regulates AMPA receptor expression in hippocampal neurons. Proc. Natl. Acad. Sci. U S A. 109, 1323-1328. doi: 10.1073/pnas.1113736109
Raab-Graham, K. F., and Niere, F. (2017). mTOR referees memory and disease through mRNA repression and competition. FEBS Lett. 591, 1540-1554. doi: 10.1002/1873-3468.12675

Rao-Ruiz, P., Rotaru, D. C., van der Loo, R. J., Mansvelder, H. D., Stiedl, O., Smit, A. B., et al. (2011). Retrieval-specific endocytosis of GluA2-AMPARs underlies adaptive reconsolidation of contextual fear. Nat. Neurosci. 14:1302. doi: 10.1038/nn.2907

Renner, M. C., Albers, E. H., Gutierrez-Castellanos, N., Reinders, N. R., van Huijstee, A. N., Xiong, H., et al. (2017). Synaptic plasticity through activation of GluA3-containing AMPA-receptors. eLife 6:e25462. doi: 10.7554/eLife.25462

Riedel, G., Micheau, J., Lam, A. G. M., Roloff, E. V. L., Martin, S. J., Bridge, H., et al. (1999). Reversible neural inactivation reveals hippocampal participation in several memory processes. Nat. Neurosci. 2, 898-905. doi: 10.1038/13202

Rodriguez-Ortiz, C. J., Balderas, I., Garcia-DeLaTorre, P., and Bermudez-Rattoni, F. (2012). Taste aversion memory reconsolidation is independent of its retrieval. Neurobiol. Learn. Mem. 98, 215-219. doi: 10.1016/j.nlm.2012.08.002

Rossmann, M., Sukumaran, M., Penn, A. C., Veprintsev, D. B., Babu, M. M., and Greger, I. H. (2011). Subunit-selective N-terminal domain associations organize the formation of AMPA receptor heteromers. EMBO J. 30, 959-971. doi: $10.1038 /$ emboj.2011.16

Roy, D. S., Arons, A., Mitchell, T. I., Pignatelli, M., Ryan, T. J., and Tonegawa, S. (2016). Memory retrieval by activating engram cells in mouse models of early Alzheimer's disease. Nature 531, 508-512. doi: 10.1038/nature17172

Rozov, A., Sprengel, R., and Seeburg, P. H. (2012). GluA2-lacking AMPA receptors in hippocampal CA1 cell synapses: evidence from gene-targeted mice. Front. Mol. Neurosci. 5:22. doi: 10.3389/fnmol.2012.00022

Rugg, M. D., Johnson, J. D., Park, H., and Uncapher, M. R. (2008). Encodingretrieval overlap in human episodic memory: a functional neuroimaging perspective. Prog. Brain Res. 169, 339-352. doi: 10.1016/S0079-6123(07)0002120

Rugg, M. D., Johnson, J. D., and Uncapher, M. R. (2015). "Encoding and retrieval in episodic memory," in The Wiley Handbook on the Cognitive Neuroscience of Memory, eds D. R. Addis, M. Barense, and A. Duarte (Hoboken, NJ: Wiley Blackwell), 84-107.

Saglietti, L., Dequidt, C., Kamieniarz, K., Rousset, M. C., Valnegri, P., Thoumine, O., et al. (2007). Extracellular interactions between GluR2 and N-cadherin in spine regulation. Neuron 54, 461-477. doi: 10.1016/j.neuron.2007.04.012

Sans, N., Vissel, B., Petralia, R. S., Wang, Y. X., Chang, K., Royle, G. A., et al. (2003). Aberrant formation of glutamate receptor complexes in hippocampal neurons of mice lacking the GluR2 AMPA receptor subunit. J. Neurosci. 23, 9367-9373. doi: 10.1523/JNEUROSCI.23-28-09367.2003

Schwenk, J., Baehrens, D., Haupt, A., Bildl, W., Boudkkazi, S., Roeper, J., et al. (2014). Regional diversity and developmental dynamics of the AMPA-receptor proteome in the mammalian brain. Neuron 84, 41-54. doi: 10.1016/j.neuron. 2014.08.044

Seese, R. R., Le, A. A., Wang, K., Cox, C. D., Lynch, G., and Gall, C. M. (2020). A TrkB agonist and ampakine rescue synaptic plasticity and multiple forms of memory in a mouse model of intellectual disability. Neurobiol. Dis. 134:104604. doi: 10.1016/j.nbd.2019.104604

Seewald, A., Schönherr, S., Hörtnagl, H., Ehrlich, I., Schmuckermair, C., and Ferraguti, F. (2021). Fear memory retrieval is associated with a reduction in AMPA receptor density at thalamic to amygdala intercalated cell synapses. Front. Synaptic Neurosci. 13:634558. doi: 10.3389/fnsyn.2021.634558

Shi, S. H., Hayashi, Y., Esteban, J. A., and Malinow, R. (2001). Subunit-specific rules governing AMPA receptor trafficking to synapses in hippocampal pyramidal neurons. Cell 105, 331-343. doi: 10.1016/s0092-8674(01)00321-x

Sommer, B., Köhler, M., Sprengel, R., and Seeburg, P. H. (1991). RNA editing in brain controls a determinant of ion flow in glutamate-gated channels. Cell 67, 11-19. doi: 10.1016/0092-8674(91)90568-j

Squire, L. R., Genzel, L., Wixted, J. T., and Morris, R. G. (2015). Memory consolidation. Cold Spring Harb. Perspect. Biol. 7:a021766. doi: 10.1101/ cshperspect.a021766

Staresina, B. P., and Wimber, M. (2019). A neural chronometry of memory recall. Trends Cogn. Sci. 23, 1071-1085. doi: 10.1016/j.tics.2019.09.011

Stern, S. A., and Alberini, C. M. (2013). Mechanisms of memory enhancement. Wiley Interdisciplinary Rev. Systems Biol. Med. 5, 37-53. doi: 10.1002/wsbm. 1196 
Sun, X., Wang, N., Wang, X., Sun, L., Li, Y., and Cui, C. (2019). AMPA receptor in ventromedial prefrontal cortex plays different roles in the recent and remote retrieval of morphine-associated memory. Neurochem. Res. 44, 1939-1949. doi: 10.1007/s11064-019-02827-z

Suzuki, A., Josselyn, S. A., Frankland, P. W., Masushige, S., Silva, A. J., and Kida, S. (2004). Memory reconsolidation and extinction have distinct temporal and biochemical signatures. J. Neurosci. 24, 4787-4795. doi: 10.1523/JNEUROSCI. 5491-03.2004

Szapiro, G., Izquierdo, L. A., Alonso, M., Barros, D., Paratcha, G., Ardenghi, P., et al. (2000). Participation of hippocampal metabotropic glutamate receptors, protein kinase A and mitogen-activated protein kinases in memory retrieval. Neuroscience 99, 1-5. doi: 10.1016/s0306-4522(00)00236-230

Tanaka, H., and Hirano, T. (2012). Visualization of subunit-specific delivery of glutamate receptors to postsynaptic membrane during hippocampal long-term potentiation. Cell Rep. 1, 291-298.

Tanaka, J. I., Matsuzaki, M., Tarusawa, E., Momiyama, A., Molnar, E., Kasai, H., et al. (2005). Number and density of AMPA receptors in single synapses in immature cerebellum. J. Neurosci. 25, 799-807. doi: 10.1523/JNEUROSCI. 4256-04.2005

Tang, S. J., Reis, G., Kang, H., Gingras, A. C., Sonenberg, N., and Schuman, E. M. (2002). A rapamycin-sensitive signaling pathway contributes to long-term synaptic plasticity in the hippocampus. Proc. Natl. Acad. Sci. U S A. 99, 467-472. doi: 10.1073/pnas.012605299

Tonegawa, S., Pignatelli, M., Roy, D. S., and Ryan, T. J. (2015). Memory engram storage and retrieval. Curr. Opin. Neurobiol. 35, 101-109. doi: 10.1016/j.conb. 2015.07.009

Torquatto, K. I., Menegolla, A. P., Popik, B., Casagrande, M. A., and de Oliveira Alvares, L. (2019). Role of calcium-permeable AMPA receptors in memory consolidation, retrieval and updating. Neuropharmacology 144, 312-318. doi: 10.1016/j.neuropharm.2018.10.030

Tronche, C., Lestage, P., Louis, C., Carrie, I., and Béracochéa, D. (2010). Pharmacological modulation of contextual "episodic-like" memory in aged mice. Behav. Brain Res. 215, 255-260. doi: 10.1016/j.bbr.2010. 04.009

Tronson, N. C., and Taylor, J. R. (2007). Molecular mechanisms of memory reconsolidation. Nat. Rev. Neurosci. 8, 262-275. doi: 10.1038/nrn2090

Wang, G., Li, S., Gilbert, J., Gritton, H. J., Wang, Z., Li, Z., et al. (2017). Crucial roles for SIRT2 and AMPA receptor acetylation in synaptic plasticity and memory. Cell Rep. 20, 1335-1347. doi: 10.1016/j.celrep.2017.07.030

Warrington, E. K., and Weiskrantz, L. (1968). New method of testing long-term retention with special reference to amnesic patients. Nature $217,972-974$. doi: $10.1038 / 217972 \mathrm{a} 0$

Weiskrantz, L. (1966). “Experimental studies of amnesia," in Amnesia, eds C. W. M. Whitty and O. L. Zangwill (London: Butterworths).

Wenthold, R. J., Petralia, R. S., and Niedzielski, A. S. (1996). Evidence for multiple AMPA receptor complexes in hippocampal CA1/CA2 neurons. J. Neurosci. 16, 1982-1989. doi: 10.1523/JNEUROSCI.16-06-01982.1996

Wezenberg, E., Verkes, R. J., Ruigt, G. S., Hulstijn, W., and Sabbe, B. G. (2007). Acute effects of the ampakine farampator on memory and information processing in healthy elderly volunteers. Neuropsychopharmacology 32, 12721283. doi: 10.1038/sj.npp.1301257

Whitlock, J. R., Heynen, A. J., Shuler, M. G., and Bear, M. F. (2006). Learning induces long-term potentiation in the hippocampus. Science 313, 1093-1097. doi: $10.1126 /$ science. 1128134

Winters, B. D., and Bussey, T. J. (2005). Glutamate receptors in perirhinal cortex mediate encoding, retrieval, and consolidation of object recognition memory. J. Neurosci. 25, 4243-4251. doi: 10.1523/JNEUROSCI.0480-05.2005

Yasoshima, Y., Morimoto, T., and Yamamoto, T. (2000). Different disruptive effects on the acquisition and expression of conditioned taste aversion by blockades of amygdalar ionotropic and metabotropic glutamatergic receptor subtypes in rats. Brain Res. 869, 15-24. doi: 10.1016/s0006-8993(00)02397-2390

Yu, S. Y., Wu, D. C., Liu, L., Ge, Y., and Wang, Y. T. (2008). Role of AMPA receptor trafficking in NMDA receptor-dependent synaptic plasticity in the rat lateral amygdala. J. Neurochem. 106, 889-899. doi: 10.1111/j.1471-4159.2008.05461.x

Yuste, R., and Bonhoeffer, T. (2001). Morphological changes in dendritic spines associated with long-term synaptic plasticity. Annu. Rev. Neurosci. 24, 10711089. doi: 10.1146/annurev.neuro.24.1.1071

Zhang, H., and Bramham, C. R. (2020). Bidirectional dysregulation of AMPA receptor-mediated synaptic transmission and plasticity in brain disorders. Front. Synaptic Neurosci. 12:26. doi: 10.3389/fnsyn.2020.00026

Zhang, H., Zhang, C., Vincent, J., Zala, D., Benstaali, C., Sainlos, M., et al. (2018). Modulation of AMPA receptor surface diffusion restores hippocampal plasticity and memory in Huntington's disease models. Nat. Commun. 9:4272. doi: 10. 1038/s41467-018-06675-6673

Zhou, Z., Liu, A., Xia, S., Leung, C., Qi, J., Meng, Y., et al. (2018). The C-terminal tails of endogenous GluA1 and GluA2 differentially contribute to hippocampal synaptic plasticity and learning. Nat. Neurosci. 21, 50-62. doi: 10.1038/s41593017-0030-z

Conflict of Interest: The authors declare that the research was conducted in the absence of any commercial or financial relationships that could be construed as a potential conflict of interest.

Publisher's Note: All claims expressed in this article are solely those of the authors and do not necessarily represent those of their affiliated organizations, or those of the publisher, the editors and the reviewers. Any product that may be evaluated in this article, or claim that may be made by its manufacturer, is not guaranteed or endorsed by the publisher.

Copyright (C) 2021 Pereyra and Medina. This is an open-access article distributed under the terms of the Creative Commons Attribution License (CC BY). The use, distribution or reproduction in other forums is permitted, provided the original author(s) and the copyright owner(s) are credited and that the original publication in this journal is cited, in accordance with accepted academic practice. No use, distribution or reproduction is permitted which does not comply with these terms. 